\title{
Synergistic Effect of Expandable Graphite and Lanthanum Cerium Oxide on Intumescent Fire Retardant Coating for Structural Applications
}

\author{
Hammad Aziz* \\ Department of Mechanical Engineering, Universiti Teknologi PETRONAS, Bandar Seri Iskandar, 31750 Perak, Malaysia
}

ABSTRACT: Intumescent fire retardant coatings (IFRC), as a passive form of fire protection, are extensively used by the oil and gas industries to protect steel against corrosion and fire. In this study, an epoxy based IFRC was prepared with different flame retardants. IFRC was reinforced with lanthanum cerium oxide (LCO) to study its effect on thermal insulation before and after immersion in salt water for a period of one month. Characterization techniques include FESEM with EDS, TGA, XPS, XRD,and Pyrolysis GC-MS. Results demonstrated that coating with 4 wt \% LCO and 3 wt \% EG provided better thermal insulation both before and after salt water immersion and exhibited less weight loss as per TGA analysis.

\section{INTRODUCTION}

Structural steel is widely used in construction for buildings, bridges, and petroleum refineries as well as onshore and offshore structures. ${ }^{1,2}$ Exposure of unprotected steel to a corrosive environment causes the deterioration of both structural and surface properties of its iron component causing billions of dollars in losses annually. Furthermore, in the event of accidental fire, temperatures may rise to the flashover point within seconds and negatively affect the load bearing ability of structural steel leading to structural collapse after a certain period of time. Intumescent fire retardant coating (IFRC), a form of passive fire protection, has gained wide acceptance due to the formation of its expanded, thermally stable char layer., Conventional fire retardant coating contains ammonium polyphosphate, pentaerythritol, and melamine but provides inferior thermal protection and reduced stability at higher temperatures. 5 These compounds are easily oxidized at high temperatures and are also water sensitive. In addition, they readily migrate to the surface of the coating to provide no charring. ${ }^{6}$ Hence, to enhance thermal efficiency and the char layer's microstructure, different types of fillers have been introduced to the coating. ${ }^{7,8}$

The thermal efficiency of an epoxy based coating is markedly affected by immersion in salt water whereby no char is formed due to chloride ion attacks on melamine ${ }^{9}$ and also ionic exchange with APP and $\mathrm{Na}^{+}$. Some researchers have demonstrated that certain binders and fillers having parallel particle shape, e.g., expandable graphite ${ }^{5}$ and glass flake, ${ }^{10}$ have efficiently improved fire-retardant/resistant performance in corrosive environments.

Rare earth oxides such as lanthanum and cerium oxides are widely employed in the chemical industrial sector due to their impressive properties as catalysts ${ }^{11,12}$ for hydrogenation, esterification, etc. For intumescent systems, char forms from dehydrogenation and esterification reactions between acids and carbon rich compounds, ${ }^{13}$ so it is expected that LCO holds an expected flame retardant outcome.

The durability of an epoxy based IFRC with lanthanum cerium oxide (LCO) in a corrosive environment is presented below. LCO efficiently improved the coating's fire resistance even after immersion in a corrosive environment-likely due to its flake-shaped particle-when challenged by a small scale hydrocarbon fire test.

\section{EXPERIMENTAL PROCEDURE}

Materials. Ammonium polyphosphate (APP: acid source) containing 30\% phosphorus was purchased from Clariant. Pentaerythritol (PER: carbon source) was purchased from Merck. Melamine (MEL: blowing agent) was purchased from SABIC. Expandable graphite (EG) treated with sulfuric acid was purchased from Kaiyu Industrial HK Ltd. Lanthanum cerium oxide (LCO-inorganic filler) containing $41 \%$ cerium and $26 \%$ lanthanum was purchased from Henan Kingway Chemicals Co. Ltd., and boric acid (BA-additive) was purchased from Merck. These compounds were bound together by an epoxy resin, bisphenol A, and cured using polyamide polyamine (purchased from ACR Tech Ltd.).

Preparation of IFRC. Initially, APP-PER-MEL-BA-LCO was subjected to grinding for $1 \mathrm{~min}$ to form a homogeneous mixture. Epoxy resin, together with EG and the ground materials, was then combined by using a high shear mixer, after which a curing agent was added to finalize the coating. This coating was applied by brush to one side of a structural steel substrate. The substrate was sand blasted and cleaned with ethanol to remove remaining surface debris and to provide a better mechanical coating-substrate interlock. No primer was used on the steel substrate. The final thickness of the coating was $1.5-2.0 \mathrm{~mm}$ as measured by a PosiTector thickness measuring gauge. Samples were then left at room temperature for $24 \mathrm{~h}$ until fully cured. Three formulations were developed (see Table 1 for chemical compositions). Epoxy binder (epoxy resin + polyamide polyamine) had no effect on the fire protection performance, so for studying the synergistic effect

Received: December 15, 2014

Revised: April 14, 2015

Accepted: May 12, 2015 
Table 1. Weight \% of Ingredients in Preparing IFRC

\begin{tabular}{cccc} 
intumescent formulations & APP/PER/MEL/BA & EG/LCO & epoxy binder \\
IF-1 & $12 / 5.6 / 5.6 / 12$ & $3 / 0$ & 61.8 \\
IF-2 & $12 / 5.6 / 5.6 / 12$ & $0 / 4$ & 60.8 \\
IF-3 & $12 / 5.6 / 5.6 / 12$ & $3 / 4$ & 57.8 \\
\hline
\end{tabular}

between EG and LCO, the wt \% of the epoxy binder was changed. The SEM micrograph and EDS of LCO is shown in Figure 1. The diameter of the LCO flake is about $40-45 \mu \mathrm{m}$, while its thickness is in the range of $4-6 \mu \mathrm{m}$.

\section{MEASUREMENTS AND CHARACTERIZATION}

Thermal Insulation Test. A thermal insulation test was conducted to evaluate the effect of LCO on the thermal efficiency of the coating. A small scale hydrocarbon fire test using a portable cylinder filled with butane gas with a flow rate of $105 \mathrm{~g} / \mathrm{h}$ was used. The temperature of the flame was close to the time/temperature curve as specified in UL-1709, and it was measured by using a K-type thermocouple placed on the coated side of the substrate. Three K-type thermocouples were affixed to the uncoated side of the substrate to measure the backside temperature using glue resistant to high temperatures. Data were recorded with the ANRITSU AM8000 Compact Thermologger, which digitally displays the temperature, and the temperature was recorded every minute. For safety reasons, the substrate's temperature at $300{ }^{\circ} \mathrm{C}$ was defined as fire resistance time. The time vs temperature curves of the experimental flame versus the UL1709 standard curve are compared in Figure 2a. The lab scale furnace for conducting thermal insulation test is shown in Figure $2 b$.

Field Emission Scanning Electron Microscopy with Energy Dispersive Spectroscopy (FESEM with EDS). The microstructure and elemental composition of the char obtained after the fire test was determined by SUPRA VP55 SEM (manufactured by Carl Zeiss and equipped with the INCAx-act X-ray Detector, Oxford Instruments) under vacuum. The voltage (EHT) for the microstructure and EDS was $5 \mathrm{kV}$ and $20 \mathrm{kV}$, respectively.

Thermo Gravimetric Analysis (TGA). The residual weight of the coating was determined by TGA Q50 (PerkinElmer Inc.). Samples were run in a nitrogen atmosphere at a heating rate of $10{ }^{\circ} \mathrm{C} / \mathrm{min}$ in the temperature range from $30^{\circ} \mathrm{C}$ to $800{ }^{\circ} \mathrm{C}$.

X-ray Photoelectron Spectroscopy (XPS). The elemental composition of the char was confirmed with the K-Alpha XPS Photoelectron Spectrometer (Thermo Scientific). The spot size was $400 \mu$. Finally, the curves were fitted using Origin Pro software.

X-ray Diffraction (XRD). XRD was used to determine the char composition after the fire test. The XRD was conducted using a model number AXS D8 Advance manufactured by Bruker using $\mathrm{Cu} \mathrm{K} \alpha$ radiation with a nickel filter $(k=0.150595 \mathrm{~nm})$ in the range $\left(10^{\circ}<2 \theta<80^{\circ}\right)$.

Pyrolysis Gas Chromatography-Mass Spectrometry (GC-MS). Gases released during degradation of the coating was analyzed by using gas chromatography mass spectrometer model number GC/MS 5975C with a direct insertion probe and pyrolysis cell (GCMS-DIPPC), Agilent 7890A. The analysis was carried out using a PYRO-CHEM WILKS pyrolizer, Hewlett-Packard 5890 Series II gas chromatograph, and TRIO 1000 mass spectrometer.

Corrosion Test. Coated samples were placed in a Teflon bath containing $6 \mathrm{~g}$ of $\mathrm{NaCl} / \mathrm{L}$ of water (to maintain the $\mathrm{pH}$ between 7.5 and 8.0) at room temperature for one month. A small amount of cured coatings was set aside in a salt water bath for further characterization. After one month, samples were removed and blotted with tissue paper and then dried at room temperature for 3 days before TG analyses and the furnace test.

Thermal Margin Value (TMV). The thermal margin value was used to compare the coating's thermal performance both before and after immersion in salt water. The thermal margin value is defined in eqs 1 and $2:{ }^{14}$

$$
\eta=\frac{T_{c}-T_{b}}{T_{c}-T_{o}}
$$

The mean thermal margin value is

$$
\eta^{*}=\frac{1}{\Delta t} \int_{0}^{t \max } \eta
$$

where $T_{\mathcal{C}}, T_{\mathrm{b}}, T_{\mathrm{o}}$, and $t$ represent (i) critical temperatures of the steel substrate, (ii) the backside temperature of the steel substrate after $1 \mathrm{~h}$, (iii) the initial temperature before conducting the fire test, and (iv) time, respectively.

\section{RESULTS AND DISCUSSION}

Thermal Insulation Test. A thermal insulation test was completed for all formulations to distinguish effects from LCO on intumescent coatings and compared with uncoated steel substrate. These results are shown in Figure 3. The temperature of bared substrate reached above $500{ }^{\circ} \mathrm{C}$ within $10 \mathrm{~min}$. Each formulation shared approximately the same rise in temperature at the beginning of the tests due to thermal degradations of their respective coatings and char formations. After char was
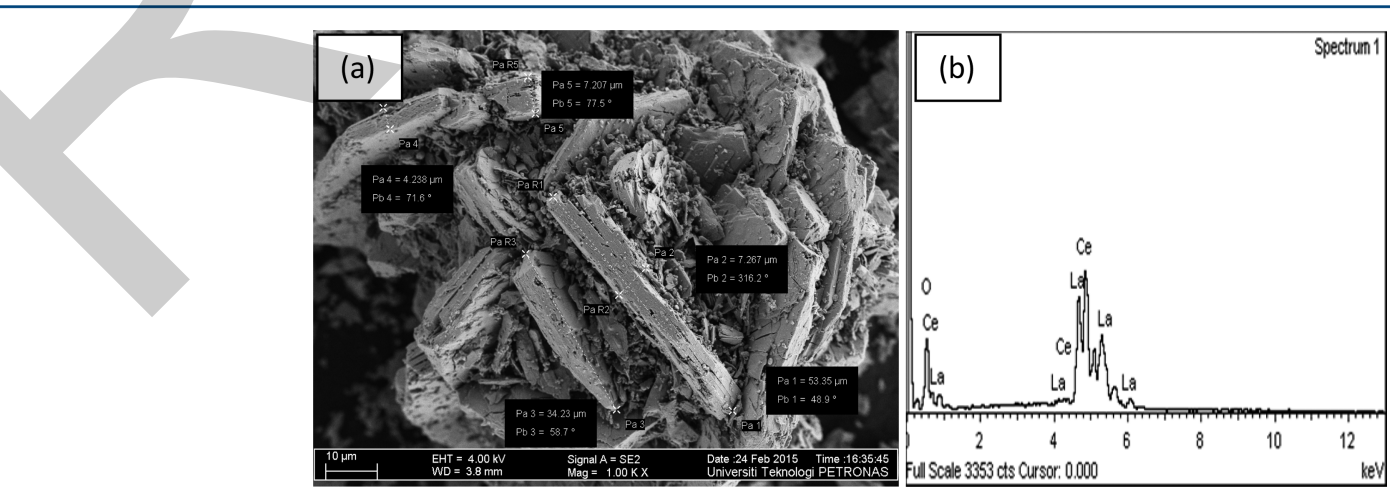

Figure 1. (a) Particle shape of LCO and (b) EDS of LCO. 

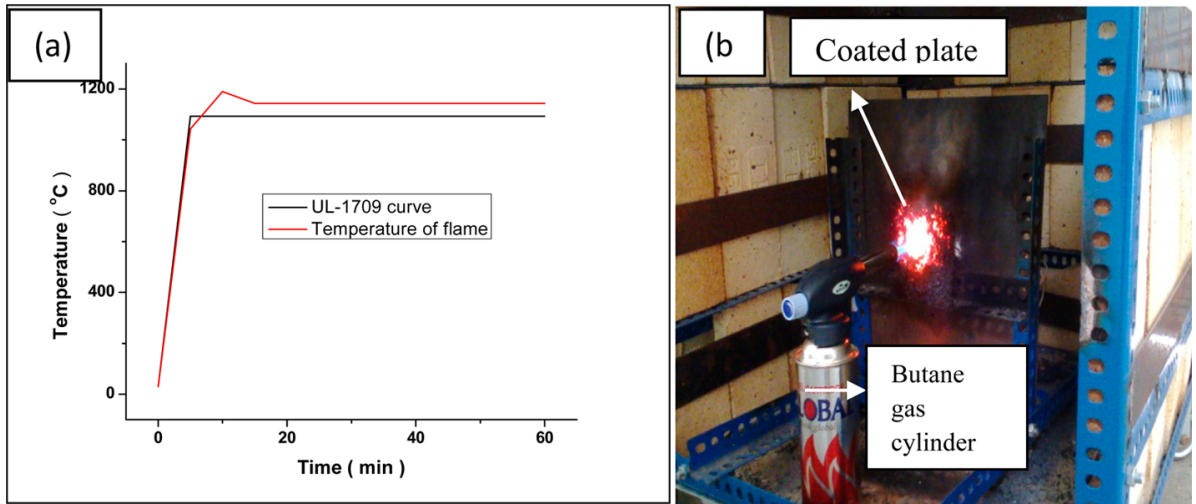

Figure 2. (a) Time vs temperature curve for experimental and referenced standard and (b) furnace for conducting thermal insulation test.

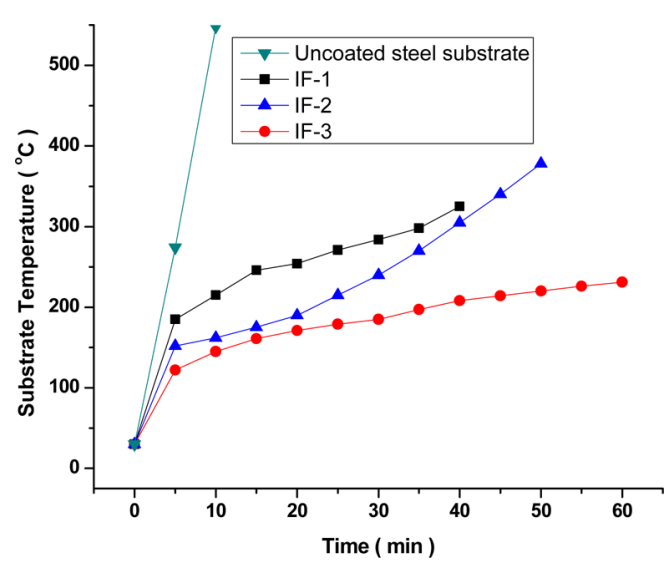

Figure 3. Time vs temperature curves for intumescent formulations.

formed from esterification reactions between APP and PER, any rise in substrate temperature was reduced due to the thermal barrier effect of the char. Fire resistant time for IF-1 was $40 \mathrm{~min}$. IF-1 did not withstand higher temperatures for a longer period. After modifying the formulation with LCO (i.e., IF-2 and IF-3), the backside temperature of the substrate was reduced. The final backside substrate temperatures for IF-2 and IF-3 were 378 and $231^{\circ} \mathrm{C}$ after $50 \mathrm{~min}$ and $1 \mathrm{~h}$, respectively.

Thus, significant enhancement in the thermal insulation property was observed after reinforcement with LCO. Hence, LCO with EG provided an improved thermally stable char of higher strength while temperatures never reached $300{ }^{\circ} \mathrm{C}$ after reinforcement. The char obtained after the fire test is shown in Figure 4. It can be seen that the char obtained from IF-1 is oxidized while, by using EG and LCO, only a little portion of char oxidized.

Table 2 represents the percentage weight loss of coated substrate before and after being subjected to the furnace test. $\mathrm{W} 1$ corresponds to the approximate weight of the coated plate before burning, while W2 is the weight of the plate after the application of the furnace test. The weight loss was reduced by using (EG+LCO) both in formulation.

FESEM with EDS. The microstructures of char layers obtained after fire tests for IF-1, IF-2, and IF-3 are shown in Figures 5 and 6. During thermal degradation of the coating, an expanded char layer formed that provided a barrier against both heat and gases. The slow diffusion of gases likely caused the char to expand. The outer surface of IF-1 has a worm-like structure due to expansion of expandable graphite as shown in
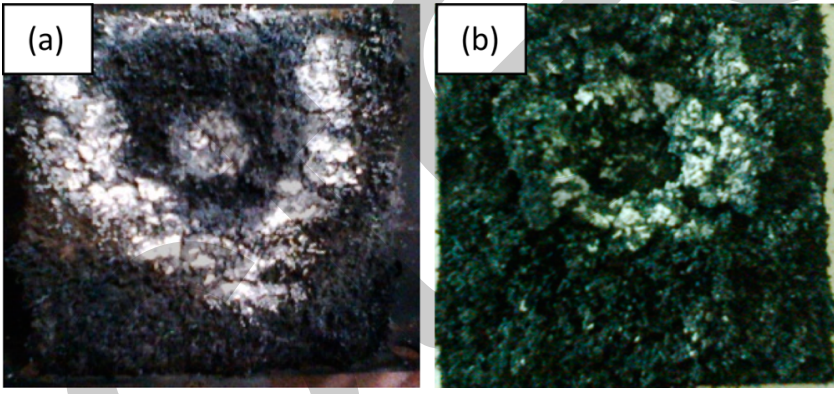

Figure 4. Char obtained after thermal insulation test for (a) IF-1 and (b) IF-3.

Table 2. Percentage Weight Loss of Formulations after Furnace Test

\begin{tabular}{|cccc} 
formulations & W1 $(\mathrm{g})$ & W2 $(\mathrm{g})$ & \% weight loss \\
\hline IF-1 & 152 & 129 & 15 \\
IF-2 & 155 & 137 & 11 \\
IF-3 & 159 & 145.5 & 8 \\
\hline
\end{tabular}

Figure 5a. The microstructure of the char obtained from IF-1 and IF-2 was compact, yet a large crack was observed on the outer surface due to the absence of inorganic filler as shown in Figure 5c,d. The crack thus produced allowed heat from the flame to penetrate the char, resulting in a loss of thermal resistance as well as in the mechanical strength of the char.

After reinforcing the coating with 4 wt \% LCO and 3 wt \% EG, the microstructure of both outer and inner char surfaces significantly offered improved thermal resistance. The outer surface contained a wormlike structure due to expandable graphite. Larger numbers of graphite flakes were therefore embedded in the char, which allowed improved thermal insulation. ${ }^{15}$ The char's outer's structure contained small bubbles possibly of inert gases such as ammonia and nitrogen that were released during the separation of APP and MEL. By reinforcement with 4 wt \% LCO, the diffusion of these gases to the outer surface was reduced, which consequently enhanced its thermal insulation property (see Figure 6). The inner surface of the char was multiporous with a uniform and homogeneous cell-size distribution. During the process of intumescence, released gases had charged the char layer that had formed by chemical reactions between APP and PER. The physical structure of the char is an important factor in effective thermal insulation. Dense, compact, and homogeneous char structures also provide desired thermal insulation qualities. ${ }^{5}$ 

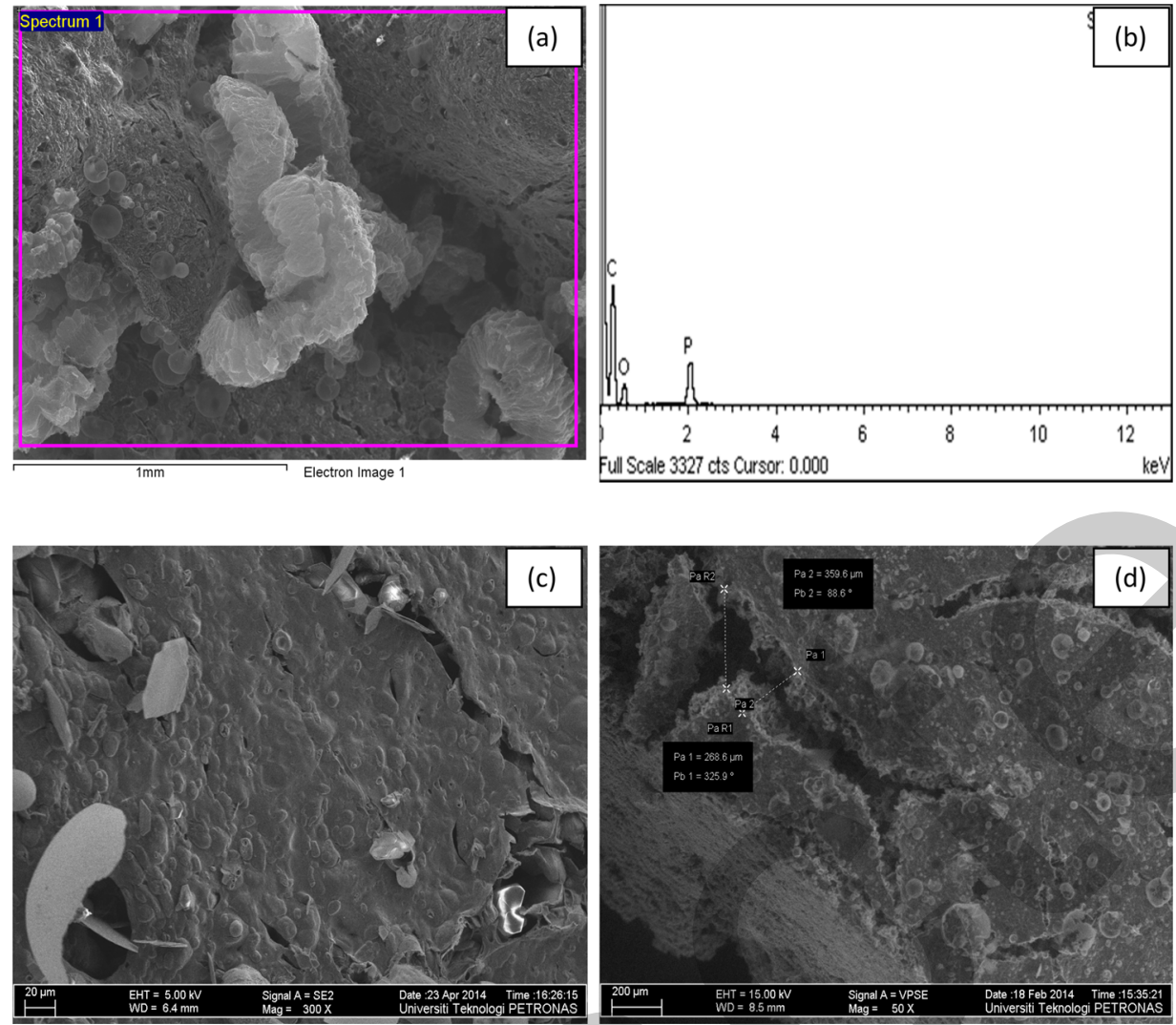

Figure 5. (a,b) EDS analysis for IF-1, (c) outer surface of IF-1, and (d) outer surface of IF-2.
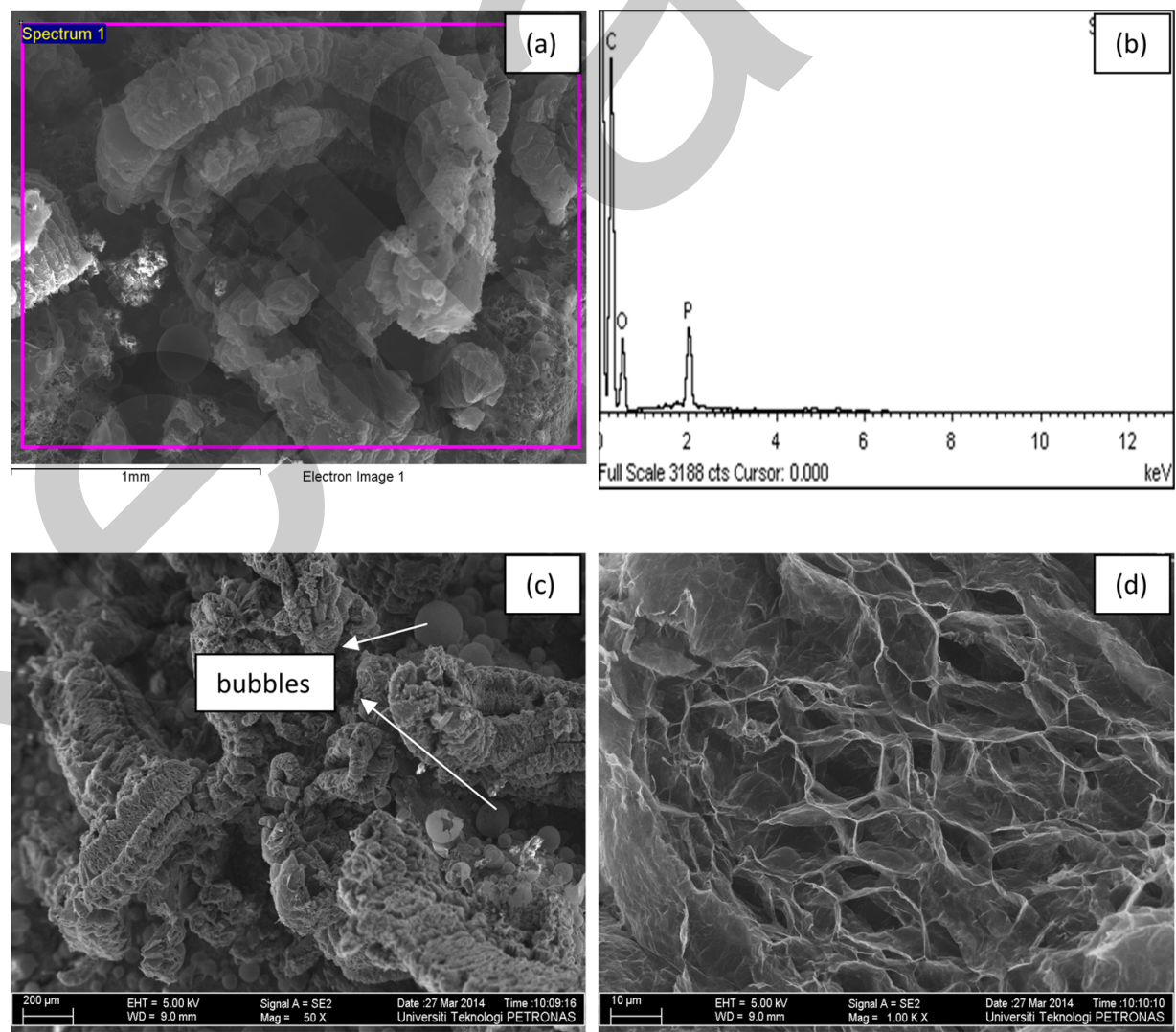

Figure 6. (a,b) EDS analysis for IF-3, (c) outer surface of IF-3, and (d) inner surface of IF-3.

IF-1 had lower weight percents of carbon compared to IF-3, while their weight percent of oxygen content remained almost the same. A higher weight percent of carbon corresponded with a stronger degree of antioxidation for the char at higher 

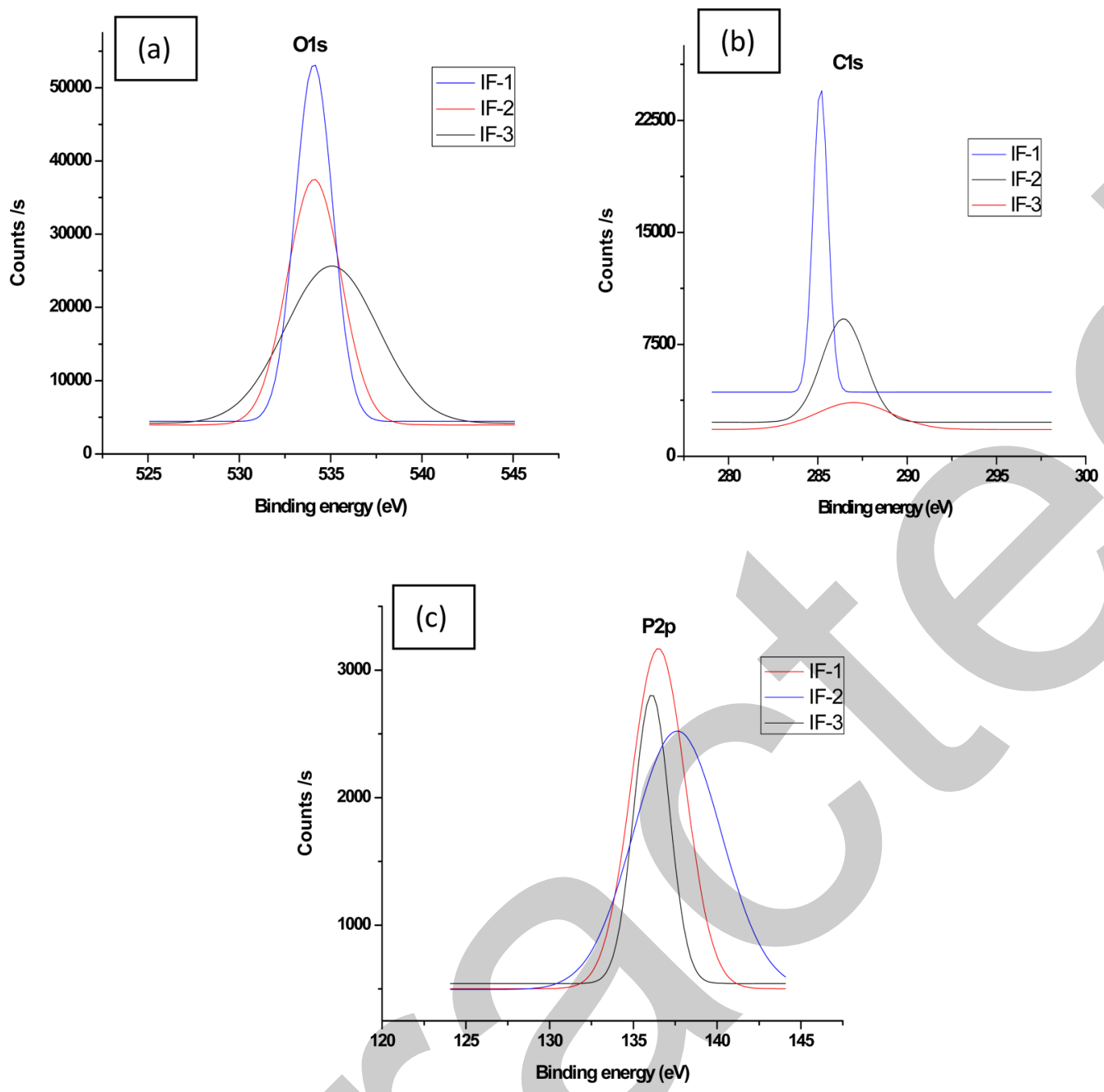

Figure 7. (a) O 1s spectra for IF-1, IF-2, and IF-3. (b) C 1s spectra for IF-1, IF-2, and IF-3. (c) P 2p spectra for IF-1, IF-2, and IF-3.

Table 3. Elemental Composition of Char Obtained from IF-1, IF-2, and IF-3

\begin{tabular}{ccccc} 
formulations & $\mathrm{C}$ & $\mathrm{O}$ & $\mathrm{P}$ & $(\mathrm{O} / \mathrm{C})$ \\
$\mathrm{IF}-1$ & 12.82 & 70.7 & 12.25 & 5.51 \\
IF-2 & 31.85 & 61.95 & 6.21 & 1.94 \\
IF-3 & 47.61 & 44.25 & 8.13 & 0.92 \\
\hline
\end{tabular}

temperatures. Boron oxide formed due to the continual dehydration of boric acid, which inhibited the oxidation of carbon at higher temperatures by forming a glass-like layer on the char's surface.

X-ray Photoelectron Spectroscopy (XPS). XPS was used to differentiate effects from LCO on the char's carbon and oxygen content. The $\mathrm{O} 1 \mathrm{~s}, \mathrm{C} 1 \mathrm{~s}$, and $\mathrm{P} 2 \mathrm{p}$ spectra for formulations studied is shown in Figure 7. Carbon content in char is specific for the degree of char accumulation while oxygen content indicates the degree of oxidation. ${ }^{16}$ Spectra obtained from IF-1, IF-2, and IF-3 for carbon, oxygen, and phosphorus are shown in Figure 7.

The oxygen-to-carbon ratio $(\mathrm{O} / \mathrm{C})$ is also an important factor determining the char's thermal stability. Reinforcement with 4 wt \% LCO significantly decreased the $(\mathrm{O} / \mathrm{C})$ ratio, thus specifying enhanced thermal stability with LCO addition. Phosphorus content was also decreased by reinforcement with LCO since APP is an acid source that decomposes to form

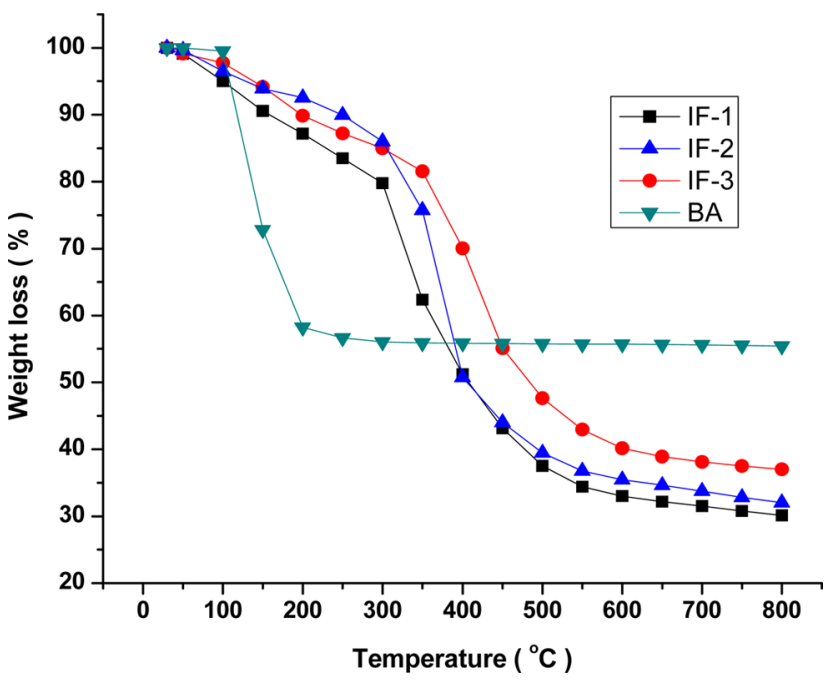

Figure 8. Residual weight for intumescent formulations studied.

phosphoric acid that then acts as a catalyst. Char forms due to an esterification reaction between APP and PER. In this case, phosphorus intensity decreased, which may account for the higher thermal stability and strength of the char. Table 3 shows the percentage of $\mathrm{C}, \mathrm{O}$, and $\mathrm{P}$ of formulations studied. 
Table 4. Initial Decomposition Temperature of Coating and Residual Weight at Different Temperatures

\begin{tabular}{ccccc} 
& & \multicolumn{3}{c}{ final residual weight $(\%)$} \\
\cline { 3 - 5 } formulations & $T_{\text {onset }}\left({ }^{\circ} \mathrm{C}\right)$ & $500{ }^{\circ} \mathrm{C}$ & $650{ }^{\circ} \mathrm{C}$ & $800{ }^{\circ} \mathrm{C}$ \\
IF-1 & 100.2 & 37.5 & 32.2 & 30.1 \\
IF-2 & 122.4 & 39.5 & 34.6 & 32.0 \\
IF-3 & 141.0 & 47.6 & 38.8 & 36.9 \\
\hline
\end{tabular}

Thermo Gravimetric Analysis (TGA). There are four different degradation stages of intumescent material, melting, intumescence, char formation, and char degradation, ${ }^{17}$ which occur at $0-200{ }^{\circ} \mathrm{C}, 200-350{ }^{\circ} \mathrm{C}, 350-450{ }^{\circ} \mathrm{C}$, and $450-$ $800{ }^{\circ} \mathrm{C}$, respectively. During the first stage, $10-15 \%$ of weight loss occurred due to the softening of the polymeric binder and release of smaller molecules from the polymer. Boric acid undergoes sequential thermal degradation during this stage. From $100-140^{\circ} \mathrm{C}$, it dehydrates to metaboric acid after which metaboric acid dehydrates to boron oxide at $140-180{ }^{\circ} \mathrm{C}$. Huang et al. defined $T_{\text {onset }}$ as the temperature where $5 \%$ weight loss occurs. ${ }^{18}$ The $T_{\text {onset }}$ for the reference coating was $100{ }^{\circ} \mathrm{C}$, and for IF-3 it was $141{ }^{\circ} \mathrm{C}$. $T_{\text {onset }}$ was significantly enhanced by LCO reinforcement. During the second stage, EG began decomposition, thus releasing carbon dioxide, which has a fire
Table 5. Gaseous Products for IF-1

\begin{tabular}{cccl}
$\begin{array}{c}\text { no. of } \\
\text { peaks }\end{array}$ & $\begin{array}{c}\text { retention } \\
\text { time }\end{array}$ & $\begin{array}{c}\text { percentage of gaseous } \\
\text { products }\end{array}$ & \multicolumn{1}{c}{ gaseous products } \\
1 & 1.986 & 0.62 & toulene \\
2 & 3.799 & 0.99 & benzaldehyde \\
3 & 3.968 & 1.13 & anilene \\
4 & 4.041 & 6.56 & phenol \\
5 & 4.788 & 29.94 & benzyl alcohol \\
6 & 4.866 & 1.01 & phenol, 2-methyl \\
7 & 5.001 & 0.45 & aniline, $n$-methyl \\
8 & 5.097 & 0.29 & phenol, 4-methyl \\
9 & 7.309 & 1.67 & phenol, 4-(1-methylethyl)- \\
10 & 8.746 & 6.91 & p-isopropenylphenol \\
11 & 16.776 & 3.27 & phenol, 2-(1-phenylethyl) \\
12 & 18.405 & 2.72 & phenol, 2-(1-phenylethyl) \\
13 & 24.885 & 21.58 & phenol, 4,4'-(1- \\
& & & methylethylidene)bis \\
14 & 27.389 & 0.54 & $\begin{array}{c}\text { hexanedioic acid, bis }(2- \\
\text { ethylhexyl) ester }\end{array}$ \\
15 & 28.933 & 0.76 & phenol, 2,4-bis(1- \\
& & & phenylethyl) \\
\hline & & &
\end{tabular}

extinguishing effect. APP decomposition released amine gases (ammonia) and was converted to phosphoric acid. MEL

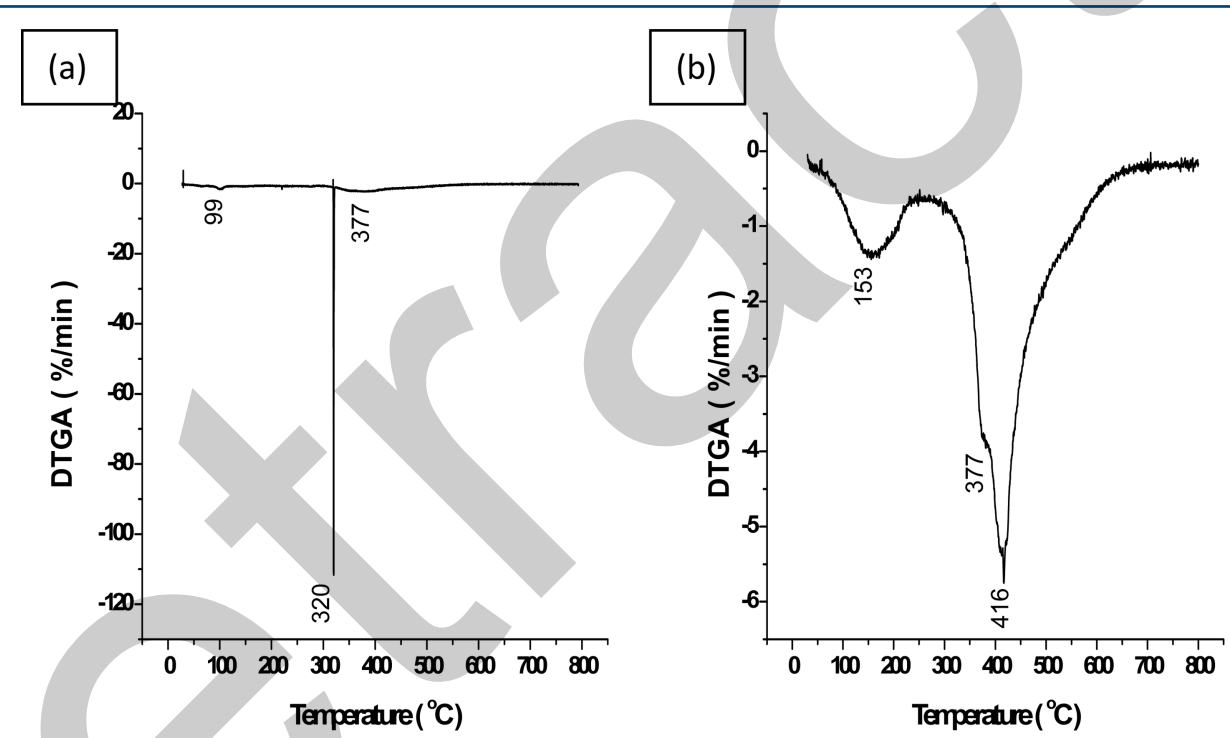

Figure 9. DTGA curves for (a) IF-1 and (b) IF-3.
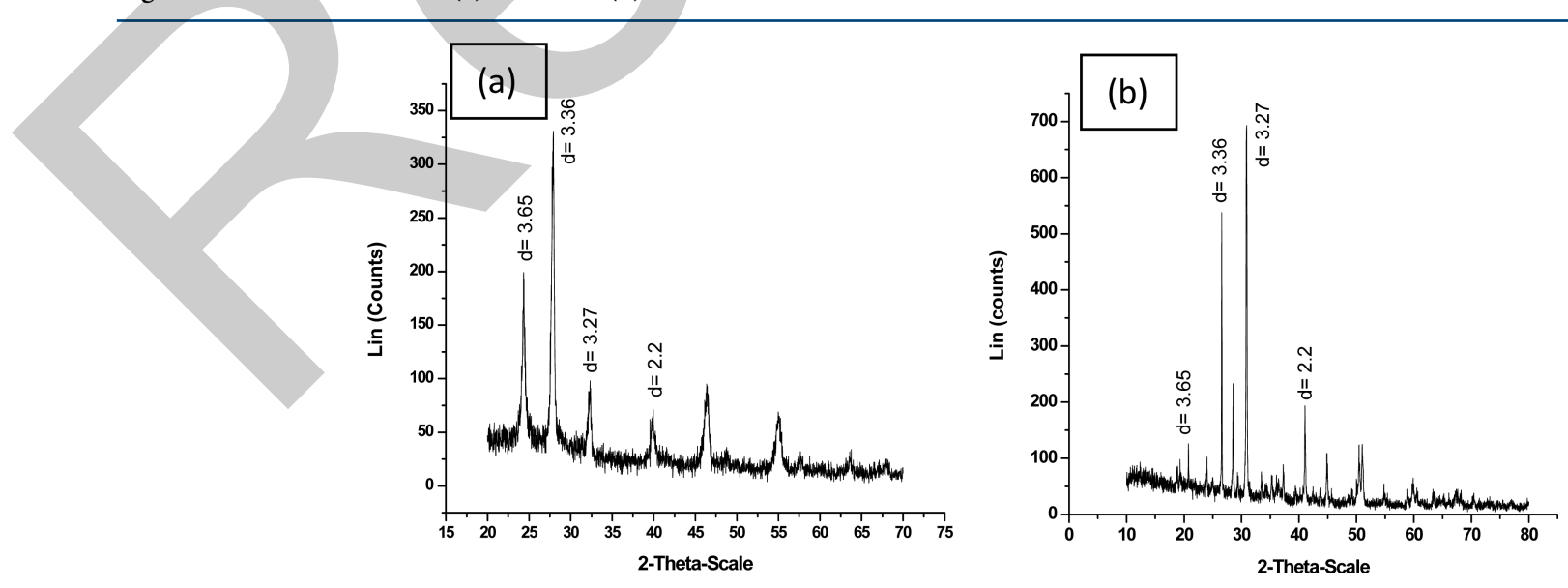

Figure 10. XRD spectra, (a) IF-2 and (b) IF-3. 
Table 6. Gaseous Products for IF-3

\begin{tabular}{cccl}
$\begin{array}{c}\text { no. of } \\
\text { peaks }\end{array}$ & $\begin{array}{c}\text { retention } \\
\text { time }\end{array}$ & $\begin{array}{c}\text { percentage of gaseous } \\
\text { products }\end{array}$ & \multicolumn{1}{c}{ gaseous products } \\
1 & 1.789 & 2.13 & toluene \\
2 & 3.210 & 4.36 & aniline \\
3 & 3.322 & 24.57 & phenol \\
4 & 4.047 & 1.62 & p-aminotoluene \\
5 & 6.001 & 6.69 & phenol, 4-(1-methylethyl)- \\
6 & 7.236 & 24.45 & p-isopropenylphenol \\
7 & 18.124 & 7.51 & dibutyl phthalate \\
8 & 22.370 & 9.69 & phenol, 4,4'-(1- \\
& & & methylethylidene)bis \\
\hline
\end{tabular}

decomposes above $290{ }^{\circ} \mathrm{C}$, thus releasing inert gases such as nitrogen and ammonia that participate in the process of intumescence. Higher weight loss occurred in the reference coating at this stage, which implied that the major volume of gases diffused into the atmosphere. IF-3 experienced an approximate weight loss of $5 \%$ at this stage. During the third stage, char formed from esterification between APP and PER, as discussed by Wang et al. ${ }^{6}$ Boron phosphate was formed due to a chemical reaction between phosphoric acid and boron oxide. In the final stage, further degradation of the char occurred, but some inorganic materials remained on the char layer. Final residual weights (at $800{ }^{\circ} \mathrm{C}$ ) for IF-1, IF-2, and IF-3 were 30.1, 32.0, and 36.9, respectively, as shown in Figure 8.

Indeed, a maximum increase of $6 \%$ residual weight is obtained. Higher residual weight enhances the degree of the antioxidation in the char, permitting it to withstand higher temperatures for a longer period. Nevertheless, no significant improvement in residual weight was observed with any increase in LCO wt \%. Table 4 shows residual weights at different temperatures.
DTGA curves for IF-1 and IF-3 are shown in Figure 9. IF-1 demonstrated three major degradation points. The first was at $99{ }^{\circ} \mathrm{C}$, corresponding with epoxy resin decomposition and the dehydration of boric acid. The second major degradation point was at $320{ }^{\circ} \mathrm{C}$, attributed to the diffusion of nonflammable gases externally that were produced during thermal degradation of the coating and, which, eventually escaped and did not participate in char formation. The third step was at $377^{\circ} \mathrm{C}$, indicating the epoxy binder's complete degradation.

IF-3 had three major degradation steps. The first occurred at $153{ }^{\circ} \mathrm{C}$ from the dehydration of the epoxy resin and of boric acid. Hence, increased LCO wt \% enhanced the degradation of epoxy resin, after which the char formed due to esterification reactions between APP and PER at $377{ }^{\circ} \mathrm{C}$. EG also contributed to the provision of a better char and process of expansion. At $416{ }^{\circ} \mathrm{C}$, further APP degradation occurred possibly by the formation of phosphate oxide, boron phosphate, lanthanum phosphate, and cerium phosphate. The observed degradation temperature of the coating therefore indicated significant enhancement by LCO reinforcement. Finally, some inorganic materials remained on the char's surface, thus preventing it from further oxidation while providing an improved thermal barrier.

X-ray Diffraction (XRD). The XRD spectra for IF-2 and IF-3 are shown in Figure 10. They are used to determine the effect of EG and LCO on the intensity of carbon (char accumulation degree). IF-2 showed peaks at a $d$ value of $d=$ $3.65(2 \theta=24.5), 3.36(2 \theta=26.5), 3.27(2 \theta=34.5)$, and 2.2 $(2 \theta=40)$ that corresponds to the presence of boron phosphate, carbon, boric acid, boron oxide, and lanthanum oxide. Boric acid has two steps for thermal degradation; first, it is dehydrated to metaboric acid, and second metaboric acid is dehydrated to boron oxide. Boron oxide is a glassy like layer formed on the surface of char. Also, chemical reaction occurred

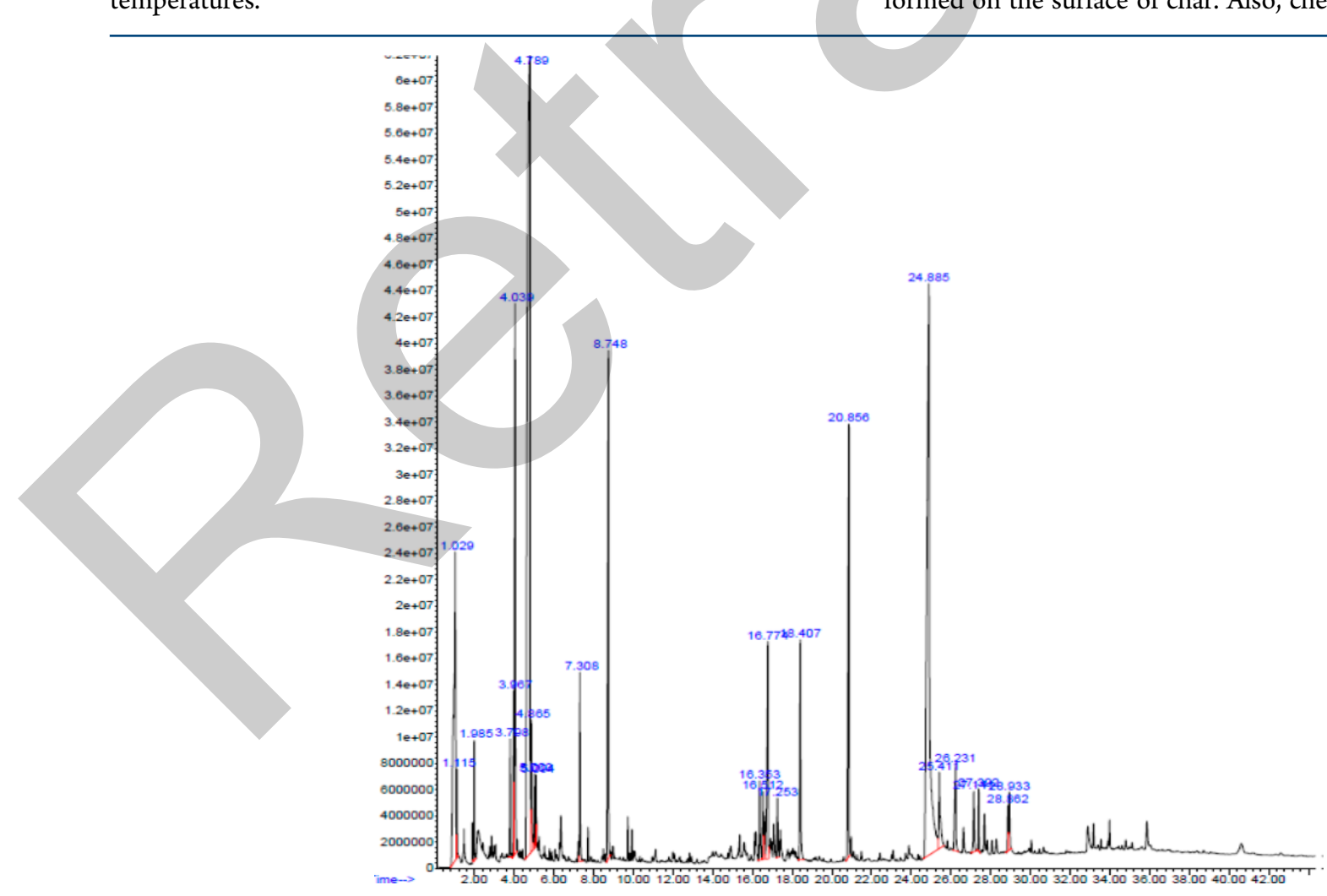

Figure 11. Chromatogram for IF-1. 


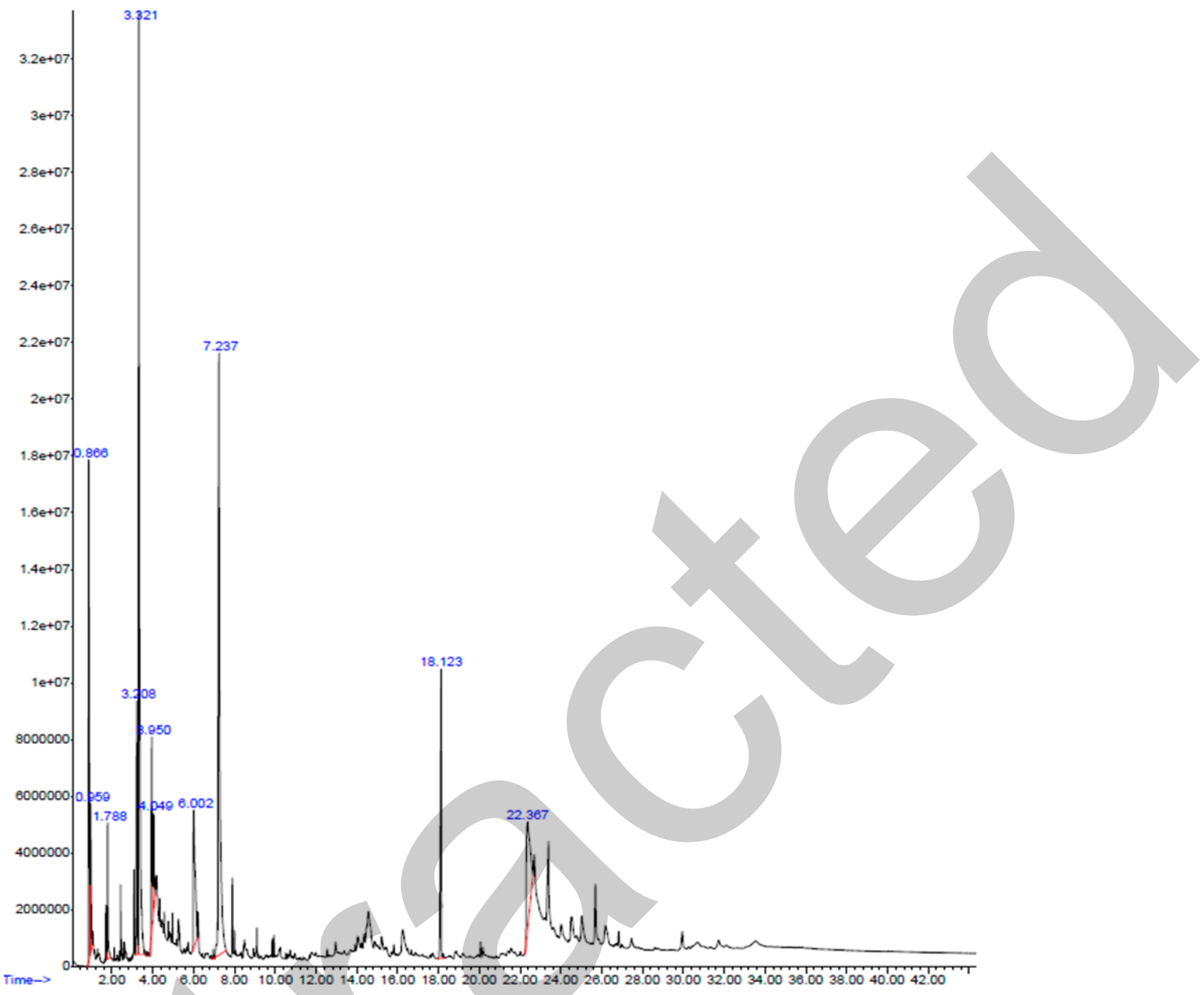

Figure 12. Chromatogram for IF-3.

between the decomposition products of APP, i.e., phosphoric acid with boron oxide to form thermally stable material (boron phosphate) up to $1200{ }^{\circ} \mathrm{C}$. IF- 2 contained 4 wt \% LCO so other peaks might correspond to lanthanum/cerium oxide. After modification with EG, i.e. IF-3, similar peaks are observed with some additional peaks that might be due to the presence of an inorganic filler. It can be seen that the intensity of carbon was improved after modifying IF-2 with EG that showed the interaction between the flame retardant additives. Higher intensity of carbon in the char corresponds to the higher antioxidation property that protects the char from oxidizing at a higher temperature.

Pyrolysis Gas Chromatography-Mass Spectrometry (GC-MS). Evolved gas analysis has been classified as two types: simultaneous and combined analysis. ${ }^{19}$ It is one of the most useful analytical techniques for the assay of volatile products released during material decomposition. Pyrolysis GC-MS is a combined analysis technique where materials are initially pyrolyzed at $600{ }^{\circ} \mathrm{C}$, after which gaseous products are analyzed. Two formulations were selected for this analysis: the IF-1 reference coating and IF-3, based on its high thermal performance.

The respective gaseous products of IF- 1 and IF- 3 are listed in Tables 5 and 6, and their chromatograms are shown in Figures 11 and 12. Major gaseous products included aromatic compounds such as aniline, quinoline, pyridine, toluene, phenol, and its derivatives. APP began to decompose above $200{ }^{\circ} \mathrm{C}$ by releasing ammonia and converting to phosphoric acid. Boric acid had two degradation steps: dehydration to metaboric acid and then to boron oxide, possibly due to the carbo-cation mechanism. Boron oxide comprised the glass-like layer that formed on the char's outer surface. The char itself was formed through esterification between APP and PER. Melamine began decomposition above $290{ }^{\circ} \mathrm{C}$ by releasing amine gases. Phosphoric acid further decomposed above $400{ }^{\circ} \mathrm{C}$, converting then to polyphosphoric acid which reacted with both boron oxide and melamine to form boron phosphate and melamine phosphate. Melamine phosphate decomposed above $450{ }^{\circ} \mathrm{C}$, at which point the epoxy resin decomposed, possibly due to the carbonium ion mechanism. ${ }^{20}$ The carbonium ion was formed due to the protonation of the APP phosphoric group followed by a skeletal rearrangement that provides a more stable carbonium ion. After this step, an olefin was generated due to the cis-elimination mechanism. Soon after olefin generation (or dienes), new aliphatic bonds formed due to exothermic polymerization. ${ }^{21}$ Finally, the expanded char was formed. Gaseous products produced during these reactions supported the formation of a dense and compact char layer in its condensed phase during the burning of the intumescent coating. ${ }^{22}$ These gaseous products were trapped 

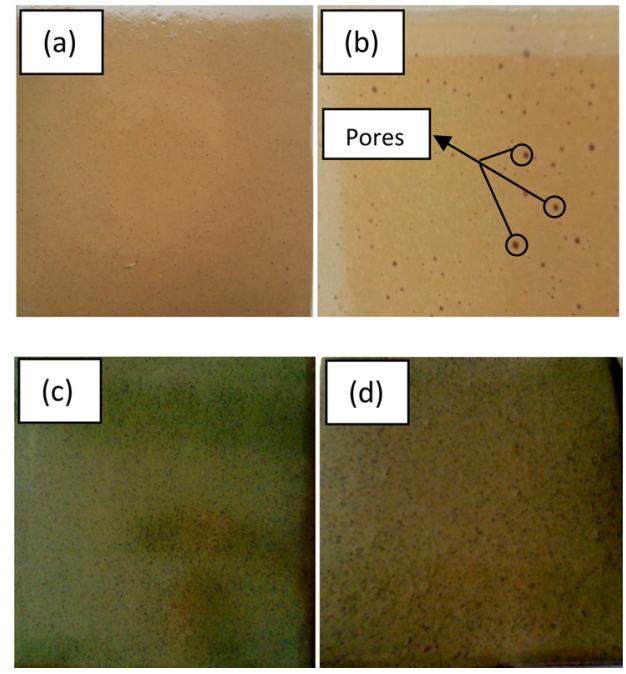

Figure 13. Visual pictures for IF-1 and IF-3, $(\mathrm{a}, \mathrm{c})$ before aging and $(\mathrm{b}, \mathrm{d})$ after aging.

within the char and thus prevented substrate combustion. The major gaseous products for IF-1 were benzyl alcohol and phenol, 4,4'-(1-methylethylidene)bis. By reinforcement with LCO at 4 wt \% (i.e., IF-3), the degradation of phenol, 4,4'-(1methylethylidene)bis was further reduced as higher gaseous percentages were achieved for both. The presence of $4 \mathrm{wt} \%$ LCO also reduced the decomposition of the epoxy resin. APP's negative effects, from $300-600{ }^{\circ} \mathrm{C}$, might have been caused by the presence of LCO. These negative effects influence the formation of phosphoric acid and the dehydration and carbonization reactions of APP with boric acid, melamine, and LCO. However, above $600{ }^{\circ} \mathrm{C}$, a more thermally stable char was formed due to the presence of inorganic materials on the char's surface.

LCO reinforcement reduced the quantities of gaseous products and the decomposition of epoxy resin since the initial decomposition temperature of IF-3 was higher compared to IF-1. Hence, less gaseous products were released during the pyrolysis of IF-3, incidentally indicating it is also environment friendly.

Corrosion Test. A corrosion test was conducted to compare the effect of LCO on thermal insulation and weight loss. Some pores were observed on the outer surface of IF-1 and IF-3 coatings due to salt water permeation. However, it is also

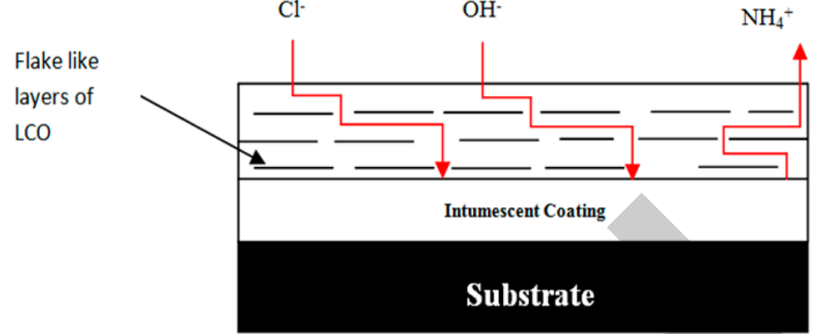

Figure 15. Schematic diagram for barrier effect of LCO.

possible that flame retardants, APP and PER, due to their respective hydrophilic characteristics, might have migrated to the surface of the coating to dissolve in water, resulting in a weight loss for the coating. ${ }^{23,24}$ Thermal insulation tests were conducted on IF-1 and IF-3 after a month's exposure in a corrosive environment. The backside temperature of the steel substrates, post-30 min for IF-1 was 299 and $248{ }^{\circ} \mathrm{C}$ for IF-3, respectively, after $1 \mathrm{~h}$ [see Figure 13a]. The thermal insulation property of the coating absent LCO was significantly decreased. Hence, (EG+LCO) reinforced coating exhibited superior thermal insulation even after exposure in a corrosive environment. Due to the hydrolytic nature of APP, ammonium ions in salt solution are produced. Ammonium chloride forms due to a reaction between chloride ions in $\mathrm{NaCl}$ and ammonium ions which catalyze hydrolysis. ${ }^{25,26}$ Due to the reaction between MEL and chloride ions, ammeline and cyanuric acids are produced. All of these newly formed compounds are watersoluble. The pores produced in IF-1 during salt-water permeation of the coating help propagate the fire toward the substrate in addition to affecting thermal insulation characteristics of the coating while disturbing the expansion of the char layer. Figure 13 shows the visual pictures of the coating before and after aging for IF-1 and IF-3.

Figure 14a shows thermal insulations for IF-1 and IF-3. TGA was performed on IF-1 and IF-3 coatings exposed to the corrosive environment to determine weight loss. The final residual weights at $800{ }^{\circ} \mathrm{C}$ were 25.54 and $31.98 \%$, respectively, as shown in Figure 14b. Reasons for the weight loss were stated above.

LCO has flake-like structures that enhance permeation and the solvation process of flame retardant additives. These flakelike structures also enhance the diffusion path and delay the
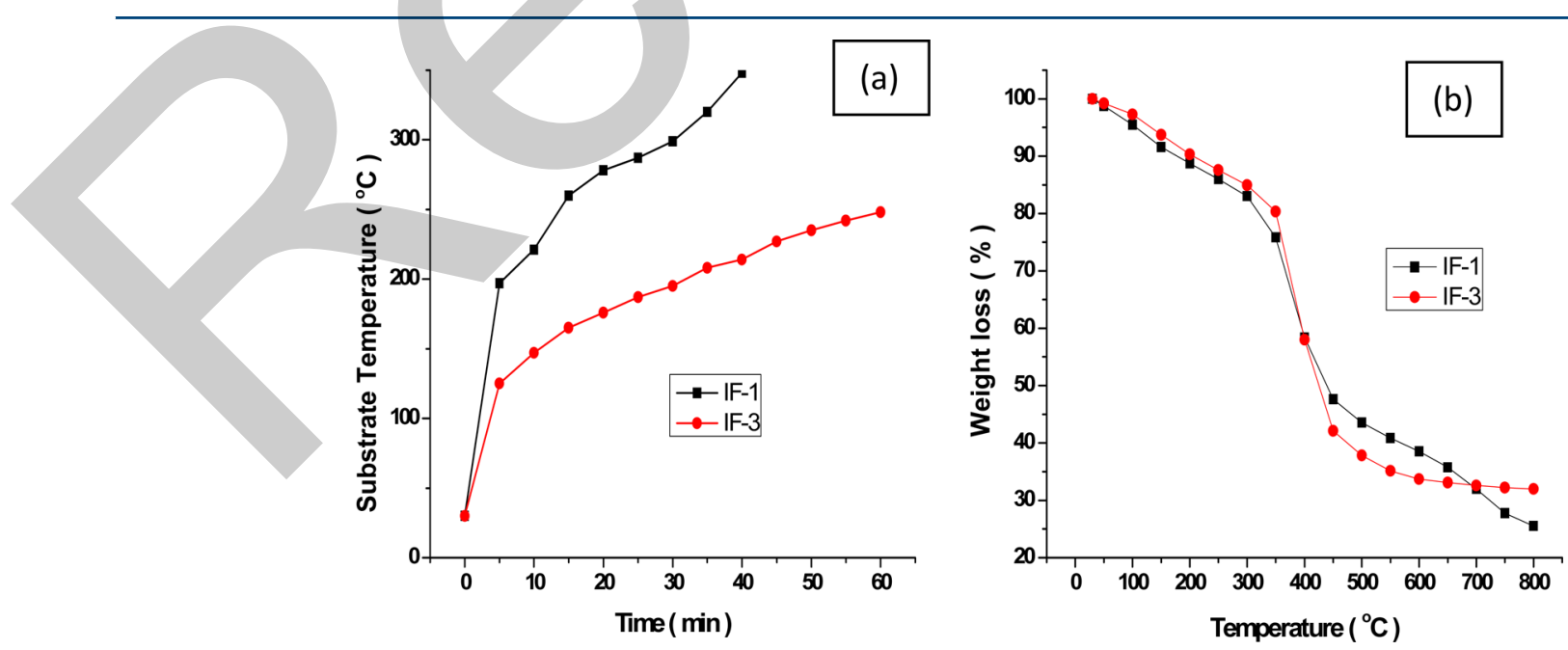

Figure 14. (a) Thermal insulation curve and (b) TGA curves. 
formation of ammonium chloride and newly water-soluble products. A schematic diagram for the "barrier effect" offered by LCO is presented in Figure 15.

Table 7 shows the comparison between thermal insulation test and TGA before and after being subjected to aging for one month for IF-1 and IF-3.

Table 7. Comparison between Thermal Insulation and Residual Weight of Formulations before and after Aging

\begin{tabular}{cccccc} 
& \multicolumn{2}{c}{$\begin{array}{c}\text { backside temperature of substrate } \\
\left({ }^{\circ} \mathrm{C}\right)\end{array}$} & & \multicolumn{2}{c}{$\begin{array}{c}\text { residual weight of } \\
\text { coating }(\%)\end{array}$} \\
\cline { 2 - 3 } \cline { 5 - 6 } formulations & before aging & after aging & & $\begin{array}{c}\text { before } \\
\text { aging }\end{array}$ & $\begin{array}{c}\text { after } \\
\text { aging }\end{array}$ \\
IF-1 & 284 after $30 \mathrm{~min}$ & 299 after 30 min & & 30.1 & 25.54 \\
IF-3 & 185 after 30 min & 195 after 30 min & 36.9 & 31.98 \\
\hline
\end{tabular}

Thermal Margin Value. Thermal margin values were calculated for IF-1 and IF-3 before and after immersion in salt water as shown in Figure 16. $T_{\mathcal{c}}, T_{\mathrm{o}}$, and $t$ are constant

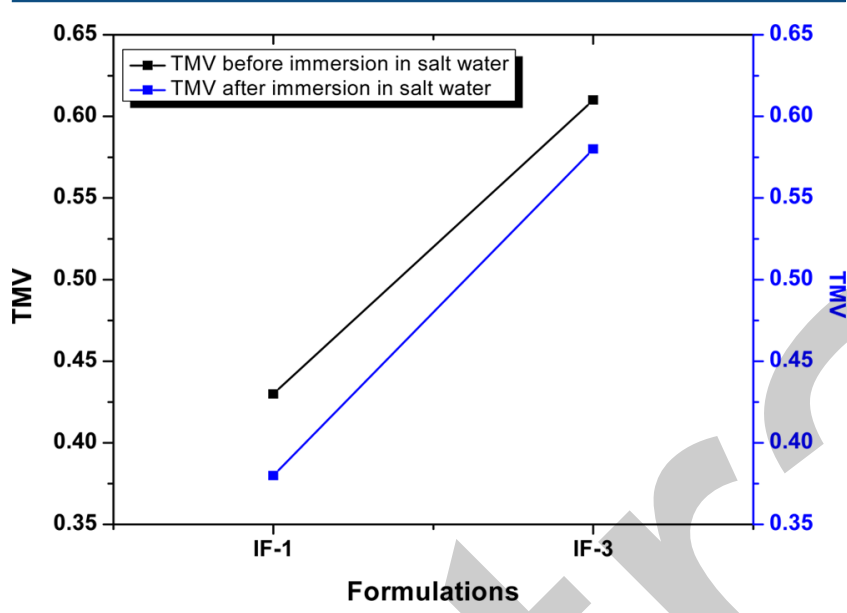

Figure 16. Thermal margin value before and after immersion in salt water.

quantities; $T_{\mathrm{b}}$ is the only variable. As the $T_{\mathrm{b}}$ value is lowered, TMV approaches unity, thus enhancing thermal performance. The slight difference in TMV for IF-3 implied that LCO provided better thermal insulation even after exposure to a corrosive environment. LCO was more properly dispersed within the coating, thus enhancing the path of water molecules to permeate the coating.

\section{CONCLUSION}

Lanthanum cerium oxide is an attractive reinforcement filler for use in an intumescent fire retardant coating. In this study, IFRCs were prepared with and without (EG+LCO) reinforcement to study their synergistic effect. Flake-like particles of LCO enhanced thermal insulation time as well as the antioxidation property of the char by delaying permeation and the solvation of flame retardant additives. Furthermore, a dense, uniform, and multiporous char structure was obtained that prevented nonflammable gas release during the thermal degradation of the coating. These results demonstrated the char's thermal stability at higher temperatures. However, increasing LCO wt \% did not significantly improve residual weight. Moreover, less toxic gases were released during pyrolysis of the coating, thus indicating it is also environmentally friendly.
The intensity of carbon was appreciably enhanced by combining both EG and LCO. Therefore, the incorporation of LCO in an intumescent system for corrosion resistance and the thermal insulation of a steel substrate appear exceptionally attractive for use in structural applications such as buildings and onshore/offshore structures to prevent corrosion and reduce the incidence of uncontrolled fires.

\section{AUTHOR INFORMATION}

\section{Corresponding Author}

*E-mail: engr.hammad.aziz03@gmail.com.

\section{Notes}

The authors declare no competing financial interest.

\section{ACKNOWLEDGMENTS}

The author acknowledges the facilities and materials provided by Department of Mechanical Engineering, Universiti Teknologi PETRONAS, Malaysia.

\section{REFERENCES}

(1) Jimenez, M.; Duquesne, S.; Bourbigot, S. Multiscale experimental approach for developing high-performance intumescent coatings. Ind. Eng. Chem. Res. 2006, 45, 4500.

(2) Yew, M. C.; Ramli Sulong, N. Fire-resistive performance of intumescent flame-retardant coatings for steel. Mater. Des. 2012, 34, 719.

(3) Jimenez, M.; Duquesne, S.; Bourbigot, S. Intumescent fire protective coating: toward a better understanding of their mechanism of action. Therm. Acta 2006, 449, 16.

(4) Beheshti, A.; Heris, S. Z. Experimental investigation and characterization of an efficient nanopowder-based flame retardant coating for atmospheric-metallic substrates. Pow. Technol. 2015, 269, 22.

(5) Wang, Z.; Han, E.; Ke, W. Influence of expandable graphite on fire resistance and water resistance of flame-retardant coatings. Cor. Sci. 2007, 49, 2237.

(6) Wang, Z.; Han, E.; Ke, W. Effect of nanoparticles on the improvement in fire-resistant and anti-ageing properties of flameretardant coating. Sur. Coat. Technol. 2006, 200, 5706.

(7) Wang, Z.; Han, E.; Ke, W. Influence of nano-LDHs on char formation and fire-resistant properties of flame-retardant coating. Prog. Org. Coat. 2005, 53, 29.

(8) Wang, Z. y.; Han, E. h.; Ke, W. Fire-resistant effect of nanoclay on intumescent nanocomposite coatings. J. Appl. Polym. Sci. 2007, 103, 1681.

(9) Jimenez, M.; Bellayer, S.; Revel, B.; Duquesne, S.; Bourbigot, S. Comprehensive study of the influence of different aging scenarios on the fire protective behavior of an epoxy based intumescent coating. Ind. Eng. Chem. Res. 2013, 52, 729.

(10) Wang, G.; Yang, J. Influences of glass flakes on fire protection and water resistance of waterborne intumescent fire resistive coating for steel structure. Prog. Org. Coat. 2011, 70, 150.

(11) Znak, L.; Stołecki, K.; Zieliński, J. The effect of cerium, lanthanum and zirconium on nickel/alumina catalysts for the hydrogenation of carbon oxides. Catal. Today 2005, 101, 65.

(12) Zhou, R.; Cao, Y.; Yan, S.-r.; Fan, K.-n. Rare earth (Y, La, Ce)promoted V-HMS mesoporous catalysts for oxidative dehydrogenation of propane. Appl. Catal. A: Gen. 2002, 236, 103.

(13) Camino, G.; Martinasso, G.; Costa, L. Thermal degradation of pentaerythritol diphosphate, model compound for fire retardant intumescent systems: Part I-Overall thermal degradation. Polym. Degrad. Stab. 1990, 27, 285.

(14) Koo, J. Thermal characterization of a ceramic intumescent material. Fire Technol. 1998, 34, 59.

(15) Li, G.; Liang, G.; He, T.; Yang, Q.; Song, X. Effects of EG and $\mathrm{MoSi}_{2}$ on thermal degradation of intumescent coating. Polym. Degrad. Stab. 2007, 92, 569. 


$$
e^{e^{e^{2}}}
$$

